\title{
Notice to: Promoting where, when and what? An analysis of web logs by integrating data mining and social network techniques to guide ecommerce business promotions
}

This notice clarifies the relationship between 'Promoting where, when and what? An analysis of web logs by integrating data mining and social network techniques to guide ecommerce business promotions. Authored by: Muhaimenul Adnan, Mohamad Nagi, Keivan Kianmehr, Radwan Tahboub, Mick Ridley, Jon Rokne. Social Network Analysis and Mining. 2011 Vol. 1: 3. DOI 10.1007/s13278-0100015-3' and 'The economic benefts of web mining; Authored by: David Kinzel, Micah Klettke, Paul Uppal, Naheed Visram, Keivan Kianmehr, Reda Alhajj, Jon Rokne. (2009) IEEE/ACM International Conference on Advances in Social Networks Analysis and Mining. DOI 10.1109/ASONAM.2009.77.'

The two articles were examined following the Committee on Publication Ethics (COPE, www.pub licationethics.org) guidelines with regard to suspected redundant publication. The article published in Social Network Analysis and Mining is an extended version of the conference paper published in Advances in Social Networks Analysis and Mining. This latter paper should have been referenced.

\section{Reference}

Kinzel D, Klettke M, Uppal P, Visram N, Kianmehr K, Alhajj R, Rokne J (2012) Social network analysis and mining, 2009. In: ASONAM '09. International conference on advances in social networks analysis and mining, pp 25-32. ISBN:978-0-7695-3689-7. 